\title{
COREOCARTOGRAFIA FAMILIAR, LINHAS DE FUGA E...: REFLEXÕES SOBRE CRIAÇÕES EM DANÇA COMO MODOS DE DILATAÇÃO DA VIDA
}

\author{
FAMILY CHOREOCARTOGRAPHY, ESCAPE LINES AND...: THOUGHTS ABOUTH \\ DANCE CREATIONS AS WAYS OF EXPANDING LIFE
}

Juanielson Alves Silva ${ }^{1}$

\begin{abstract}
Resumo: O ensaio põe em pensamento aquilo que denomino de Coreocartografia familiar, visto como um procedimento estético-poético em dança, no qual o mote poético entrelaça o corpo do intérprete criador em dança em suas relações de estranhamento e familiarização com seus processos de subjetividades. Para tal, o estudo toma como suporte teórico autores como Deleuze (1998, 1995) com conceitos de linhas de fuga e cartografia e Foucault (1984) com os conceitos de cuidado de si e estética da existência, configurando deslocamentos interpretativos para os processos criadores em dança. Argumenta-se que o intérprete criador em dança é criador e criatura dos seus processos artísticos e estéticos, enfatizando o íntimo processo de singularidade no ato artísticos poéticos em dança.
\end{abstract}

Palavras-chave: Coreocartografia Familiar; linhas de fuga; processo criativo.

\begin{abstract}
The essay brings to mind what I call family choreocartography, seen as an aestheticpoetic procedure in dance, in which the poetic motto intertwines the body of the creative interpreter in dance in its relations of strangeness and familiarization with its subjectivity processes. To this end, the study takes as theoretical support authors such as Deleuze $(1998,1995)$ with concepts of escape lines and cartography and Foucault (1984) with the concepts of self-care and aesthetics of existence, configuring interpretive shifts for creative processes in dance. It is argued that the creative interpreter in dance is the creator and creature of his artistic and aesthetic processes, emphasizing the intimate process of singularity in the poetic artistic act in dance.
\end{abstract}

Keywords: Family Corecartography; escape lines; creative process.

\section{Introdução}

$O$ fato de o homem ser uma singularidade e, como todo caso único, não se repetir, deve encorajá-lo a viver segundo sua própria lei e medida. Ele tem de mostrar por que nasceu em determinada época, e não em outra, pois, só desse modo, fará justiça a seu próprio tempo. Rosa Maria Dias

Coreocartografia familiar (SILVA, 2019) é um procedimento criado em minha pesquisa de mestrado pelo Programa de Pós-graduação em Artes da UFPA, intitulada Farinha poética: a coreocartografia familiar de um rito artístico, e que segue sendo estruturado em meu processo de doutoramento pelo mesmo programa de pós-graduação na pesquisa, até então, denominada Coreocartografia familiar: dispositivos metodológicos para pesquisa e criação em Dança.

A se saber, a Coreocartografia familiar é apresentada como um procedimento estéticopoético para pesquisa e criação em dança inspirada na cartografia (DELEUZE; GUATTARI,

\footnotetext{
${ }^{1}$ Doutorando do Programa de Pós-graduação em Artes da UFPA. E-mail: juanielsonsilva@gmail.com.
} 
1995) em diálogo com os processos de criação (SALLES, 2006) em dança contemporânea (SILVA, 2005) e sua fundamentação parte do princípio de que determinadas criações em dança emergem principalmente das relações de estranhamento e familiarização de si no corpo que dança, relações estas que se dão em rede e são constituídas a partir das experiências coreocorpográficas do sujeito no mundo, isto é, seus processos de subjetividade.

Assim sendo, e como forma de ampliar as perspectivas sobre a Coreocartografia familiar, em minha tese de doutorado, pretendo apresentar três dinâmicas coreocartográficas, temporariamente nomeadas como: Reapropriação da procura que se apresenta como uma tomada de consciência sobre as potências subjetivas nos procedimentos (contra)metodológicos e nos modos de escrita das pesquisas acadêmicas em dança, principalmente nas pesquisas com fins performativos; Reapropriação do fazer que desvela-se a partir das experimentações corporais e composição coreográfica que tomam as escritas corporais autobiográficas como dispositivos para autonomia criativa do corpo que dança; e Reapropriação do viver que toma as prática em dança como modos de dilatação da vida, isto é, como estratégias para a subversão das estruturas fixas dos sistemas sócio-políticos que tendem a circunscrever os corpos dançantes.

Claro, é importante ressaltar que, esta organização não tem como intenção a separação pragmática destes processos, uma vez que eles acontecem de forma transversal e não linear, e se propõe a reafirmar o lugar da pesquisa e da criação em dança como espaço para um fluxo contínuo, aberto e de não aprisionamento do pensamento em categorias.

Dito isto, ressalto que, as considerações apresentadas neste trabalho tem como recorte/indutor alguns aspectos da terceira dinâmica coreocartográfica, isto é, a reapropriação do viver, pois trata-se de uma reflexão sobre como as práticas em dança autobiográficas tornamse estratégias para a subversão das estruturas fixas dos sistemas sócio-políticos, e porque estas podem ser consideradas práticas de si que criam Linhas de fuga (DELEUZE; PARNET, 1998) e se personificam como artes da existência (FOUCAULT, 1984). Em outras palavras, buscase aqui configurar deslocamentos interpretativos para os processos criadores em dança a ponto de compreender tais processos como estilizações, dilatações ou reapropriações da vida, partindo da premissa que nestes processos se assume a ideia de que para entender a natureza das relações humanas, é necessário entender primeira e primordialmente o próprio corpo, pois é este o condutor e o cerne de toda substância moral, intelectual e artística que nos (trans)formam.

Para tal, leva-se em consideração que, na ótica das proposições contemporâneas, a dança se alicerça nos atravessamentos diversos que o corpo tem nas dinâmicas que constroem nossas subjetividades ao longo da vida, isto é, a dança sonda os limites da existência e dispõe de experimentações que ultrapassam a criação por uma finalidade de contemplação que levara o artista e/ou público a uma experiência mítico-transcendental, pois na experiência dançante projeta-se de forma mais direta uma fusão entre vida e arte que tende a questionar e subverter a ordem social pré-disposta e criar novos dispositivos para entender as relações humanas e suas reverberações, principalmente, no corpo daquele que dança.

\section{Coreografar e cartografar: práticas de si}

\section{Vinte e quatro}

Vinte e quatro era um homem de vinte quatro anos, residente do vigésimo quarto andar, que em sua infância ocupava o número vinte e quatro na chamada na escola e, por incrível que pareça, quando podia, trabalhava vinte e quatro horas por dia. Porém, naquele dia seus planos não ocorreram como esperado. 
Era uma tarde chuvosa, cheia de relâmpagos e trovões. A chuva era tão forte que fez faltar a energia e as redes de comunicação pararem de funcionar. Rede telefônica, internet, televisão, nada disso funcionava e, por esse motivo, a cidade inteira parou e todos os serviços foram cancelados, incluindo o trabalho de Vinte e quatro. Restava-lhe então, o que não lhe era nada convencional: esperar.

Já com seu dia supostamente perdido e sem poder sair de casa por conta da forte chuva que caia lá fora, Vinte e quatro, sentou-se de frente para a varanda e fez aquilo que lhe restava, isto é, olhar o céu se manifestando a sua frente.

Já no finalzinho da tarde, aos poucos, a chuva foi parando e a escuridão da noite rompendo as nuvens do céu. Eu diria até que as reinventando. E a noite, outrora praguejada por Vinte $e$ quatro que via somente no dia a possibilidade de agenciamento da vida, agora torna-se espaço de contemplação e reapropriação de um tempo e de um modo de vida que Vinte e quatro não costumava usufruir, e diante daquele acontecimento, ele se indagou:

\title{
Quanto tempo o tempo tem para pensar em si?
}

\author{
Eu danço. Danço na e para diferença. \\ E no estranhamento de corpos metáforas \\ que outrora criei, sigo reinventando-me \\ e inventando uma dança e \\ e um cuidado de si. \\ Juanielson A. Silva
}

Da dança, como noite escura que atravessa nuvens depois de uma tarde tenebrosamente chuvosa, emerge a possibilidade de dilatação da vida. Esta que se manifesta por meio de práticas anti-pungentes, isto é, práticas que estimulam o corpo a não conformidade diante de feridas causadas pela tirania em seu uso dos poderes, promove, em seus modos de fazer e pensar ${ }^{2}$ movimento, corpo e subjetividade um mergulho em si capaz de criar um trajeto de encontros que oportuniza transformações singulares no modo de ver e viver a vida. Por tanto, o corpo em prática dançante que toma como norte um íntimo processo de singularidade no ato criador se reinventa subjetivamente e desconstituir-se daquilo que constantemente lhe é símil, por meio do estranhamento de si e daquilo que outrora lhe foi familiar. Torna-se, então, uma máquina de estranhamentos e produção de desejos. Uma noite que rasga as nuvens.

E vale ressaltar que:

Um corpo livre para se manifestar torna-se expressão política, exercício de liberdade individual e coletiva. Mesmo num solo de dança, encontra-se ali a representação de uma coletividade, um acontecimento em que o corpo é atravessado por sensações, sentimentos, pensamentos e imagens que são coletivas (REIS, 2017, p. 118).

Desta forma, levar-se em consideração que o corpo em tais práticas mobiliza formas de pensamento que se transpõe pelos gestos. Torna-se um corpo que articula símbolos, (re)cria memórias e nutre estratégias para o desenvolvimento da autônima do pensamento e do senso crítico, tanto diante dos próprios modos de fazer e pensar dança, quanto diante dos outros tipos

\footnotetext{
${ }^{2}$ Em meus escritos tenho preferido o uso dos termos fazer e pensar ao invés de praticar e teorizar, pois estes dois termos tomados de significações mais próximas para os artistas da dança, carregam potências singulares que talvez permitem a superação da pragmática, dicotômica e sistemática relação entre teoria e prática em dança.
} 
de dinâmicas que se tramam a partir das relações entre os corpos em seus convívios sociais. Em outras palavras, a dança, tornando a problematização do estado das coisas sua matéria prima, permite que o artista faça da mesma um processo de reflexão e criação de si ao mesmo tempo em que faz deste processo algo a ser compartilhado, pois:

A dança pós-moderna de hoje não se interessa em apresentar corpos perfeitos, unificados pela forma, nem delineados por imperativos estéticos ou sexuais. A dança parece querer, de fato, expressar a multiplicidade corporal feita de músculos, ossos, imperfeições e qualidades do ser humano, falando de si próprios, sem disfarces e para uma plateia que se identifique com o que vê (SILVA, 2005, p. 140).

E para tal, é necessário que o artista contemple o seu íntimo em um exercício de reconhecimento, estranhamento e movimento avante diante de si, ou seja, é preciso que o artista siga caminhando. E caminhando sempre no gerúndio, ad infinitum - caminhando. Onde até mesmo as pausas são espaços para possíveis reflexões sensíveis, isto é, reflexões que nem sempre se dão nas explicações lógicas atribuídas pelo uso da razão, mas também, e talvez principalmente, pela capacidade de percepção e criação de formas sensíveis: um reconhecimento ativo das práticas poéticas como estratégias de liberdade e criação de morais e práticas de si.

E aqui, entende-se como moral, não apenas o conjunto de regras e valores propostos aos indivíduos em estatutos sociais, mas também o comportamento real destes indivíduos diante de tais regras e valores (FOUCAULT, 1984), a moral, ou melhor dizendo a moral de si, "designase, assim, a maneira pela qual eles se submetem mais ou menos completamente a um princípio de conduta" (FOUCAULT, 1984, p. 26).

A julgar que, é na contemplação do comportamento real diante da moral que nasce, ou pelo menos se estimula, a consciência sobre a conformidade, ou não conformidade, que se estabelece entre o indivíduo e as dinâmicas sociais. Pois tal contemplação estimula a indagação sobre as substâncias morais, e sobre as propostas éticas, que engendram nossos modos de viver, os regimes de poder instaurados socialmente e, consequentemente, sobre as formas de produções em dança, partindo da premissa que:

a fundação ou proclamação de uma ética(universal) sempre é uma operação de poder, de opressão, de controle social. Exceto, talvez no caso dessa Ética obedecer aos interesses de uma minoria oprimida (não oligárquica), e, nesse caso, sua proposta ética será a de uma ética de luta contra uma situação de marginalização e de privilégios alheios (VIDARTE, 2019, p. 26).

Logo, partindo da premissa que nossas práticas fazem parte de determinados sistemas, como é o caso da arte dentro do sistema cultural, que por sua vez, estão ligados a diversas instituições de ordem social que regulam o comportamento do indivíduo, tais como a família, a escola, o trabalho, a religião e o estado, estas práticas estão extensivamente ligados a moral e a ética de um povo. Escutar, pensar e escrever em, sobre e a partir de si, por tanto, talvez seja uma das atividades mais difíceis que o ser humano já tenha tentado desempenhar, pois indagarse sobre suas práticas supostamente pessoais levara-o a perceber que sua subjetividade é também um processo de construção, pois faz parte de agenciamentos que extrapolam o individual e que, por consequência, pode ser regulada e circunscrita por forças externas.

Desta forma, perceber que a arte não é um empreendimento autônomo que se dá em condição insular, acarreta dois tipos de trabalho ao artista: um primeiro trabalho de responsabilidade de cunho político-social, no qual o artista deve perceber que seu projeto poético é um conjunto de comandos 
éticos e estéticos, ligados a um tempo e a um espaço, o que deve levar o artista a consciência de si não apenas como criador, mas como criador-agente-social, "criador não só de obras mas modificador também de consciências (no sentido amplo, coletivo), que colabore ele nessa revolução transformadora, longa e penosa, mas que algum dia terá atingido o seu fim - que o artista "participe" enfim da sua época, de seu povo. (OITICICA. 1967, p. 165)

E um segundo trabalho de responsabilidade consigo mesmo, para torna-se capaz de perceber quando as forças transfiguradoras de suas práticas artistas já foram neutralizadas e reduzidas ao mero exercício de reprodução de motes criativos, dissociados tanto da sua função ética de dar forma aquilo que seu tempo anuncia, quando daquilo que seu próprio corpo deseja vociferar e, por meio de um trabalho intenso de reconhecimento desse jogo de forças, superá-lo.

Para isso, o artista deve questionar-se, toda vez que se propor a criar uma obra, sobre $o$ que, por que, para que, com quem e por quem a produzirá, o que deverá ocasionar também o questionamento sobre como a produzirá. Pois ao fazer tais questionamentos, ele toma consciência de si e de sua arte, e na inquietude diante de uma conformidade instaurada nos modos de fazê-la, pode inventar outras estratégias e criar outros caminhos para tal.

A vista disso, o processo criativo para o artista da cena, isto é, para bailarino intérpretecriador $^{3}$, também é um processo de autoconhecimento, porque, durante este, "o artista se conhece diante de um espelho construído por ele mesmo. Rasurar a possível concretização de seu grande projeto(poético) é assim, rasurar a si mesmo". (SALES, 2013, p. 134)

Por isso, é necessário questionar-se, e seguir questionando-se, diante dos modos de fazer e pensar dança, a partir das razões e dos modos pelos quais nos movimentamos por meio das, e por entre as práticas dançantes, não como quem deseja encontrar uma função pedagogicamente pragmática para a dança, mas na tentativa de manter-se em constante produção de desejo e estranhamento de si, agenciando um devir de outras possíveis estéticas e outras possíveis éticas, posto que, ao fazer tal exercício se criam prováveis linhas de fuga (DELEUZE; PARNET, 1998), isto é, desterritorializações de si, considerando que, "Fugir não é renunciar às ações[...] é o contrário do imaginário. É também fazer fugir, não necessariamente os outros, mas fazer alguma coisa fugir, fazer um sistema vazar como se fura um cano" (DELEUZE; PARNET, 1998, p. 30).

E para aqueles que não fogem, que permanecem na margem, $o$ ato de fugir magoa, já que é normalmente interpretado como uma traição.[...] é, de fato, um tipo de traição, mas a vítima não são as pessoas que ficam, mas o próprio sistema opressor: "traem-se as potências fixas"' (MORAES; JARDIM, 2017, p. 26).

E uma vez que, "existe uma relação clara entre a Fuga e a Criação, que é a possibilidade que o ser humano tem de criar, trazendo coisas à existência." (MORAES; JARDIM, 2017, p. 26), é possível pensar que, a dança, por meio do seu processo criativo, levantando questões intra-processuais e de natureza sociopolítica, torna-se prática de autoconhecimento que coadjuva a criação de artes da existência, isto é:

práticas refletidas e voluntárias através das quais os homens não somente se fixam regras de conduta, como também procuram se transformar, modificar-se em seu ser singular e fazer de sua vida uma obra que seja portadora de certos valores estéticos e responda a certos critérios de estilo. (FOUCAULT, 1984, p. 15)

\footnotetext{
${ }^{3}$ A denominação bailarino intérprete-criador é usualmente utilizado para o/a artista da dança que tanto cria quando interpreta suas próprias composições coreográficas.
} 
Trata-se, portanto de uma Coreocartografia familiar que parte do princípio de que a criação em dança, emerge principalmente das relações de estranhamento daquilo que outrora lhe foi familiar no corpo, relações dadas em rede e constituídas a partir das experiências 'coreocorpográficas' do sujeito no mundo, e neste processo de desvelar a si mesmo, geram-se outras estéticas e outras éticas provenientes de uma produção de experiências que foge da submissão a potências fixas estabelecidas como verdades universais, ou melhor dizendo, que instaura um nomadismo de vida dançante, pois assim como Nunes (2019, p. 21):

Costumo dizer que a cartografia é muito mais do que uma metodologia de pesquisa, é um estilo de vida. Enxergar o mundo e se posicionar nele de forma cartográfica implica enxergá-lo e experienciá-lo sob outra perspectiva, isto, por sua vez, implica na criação de um modo de vida próprio e singular.

É possível compreender então que a dança, criatura e criadora de uma coreocartografia familiar, não cabe em caixas que se reproduzem como produtos de fabricas, pois o bailarino interprete-criador ao dilacerar suas próprias possibilidades por meio de um trabalho técnicoreflexivo de conhecimento sobre si e sobre seus modos de fazer e pensar dança, pode espalhase em linhas de vida e desconstruir os modos gélidos de pensa-la.

Em outras palavras, a prática em dança, entendidas como uma coreocartografia familiar, isto é, como prática que permite livrar-se do aspecto cruel da existência, é capaz de dilatar a vida e reapropriar-se do viver, uma vez que "embelezar a vida é sair da posição de criatura contemplativa e adquirir os hábitos e os atributos de criador, ser artista de sua própria existência" (DIAS, 2015, p. 239). Trata-se, portanto, de um processo não somente de criar obras coreográficas, mas também, ao criar tais obras, criar vidas como tal, ou seja, uma ação artística diante de si mesmo como obra de arte.

\section{Conclusão}

Ressalto que, não há uma conclusão, tão pouco respostas já dadas e medidas codificadas, pois não me interessa fazer um bolo de receitas prontas, haja vista que, o que encontro diante de mim são caminhos a se desvelar, ou melhor, a serem inventados, sendo assim muitas questões ainda podem, e certamente vão, surgir e alterar ou reafirmar os rumos das discussões que tenho apresentado até aqui. Encontro-me, então, imerso em reflexões e possibilidades prováveis e/ou improváveis, a serem aprofundadas ao longo da pesquisa que está em andamento.

E para ser sincero, neste momento me interessam muito mais os problemas e as inquietações do que do que as resoluções, por isso não há neste trabalho uma intenção de concluir nada, mas sim uma finalidade que é apresentar considerações que serão indutoras para contínuos deslocamentos desse procedimento estético-poético em dança, a qual chamo de Coreocartografia familiar.

Além disso, não me interessa a formulação de um método com fórmulas e formas fechadas, pois mergulho na possibilidade da apresentação de dispositivos, pistas, caminhos e estratégias para a criação de uma abordagem em Artes/dança que me permita, assim como permita outros pesquisadores inventar seus próprios trajetos de pesquisa e criar alicerces para um pensamento artístico-acadêmico mais subjetivo e sensível, que tenha como referencial primeiro os corpos e as trajetórias de vida daqueles que fazem e pensam dança a partir de si, bem como que tenham como intenção não apenas a formulação de ideias e conceitos, mas também a reapropriação destes corpos e dessas vidas.

Por isso, gostaria de ressaltar que a Coreocartografia familiar pode ser considerada uma estrutura do sensível que permite a dilatação dos sentidos, da percepção, do corpo e dos 
territórios da criação, isto é, um território em constante construção e transbordamento de si: um rio fluente que escorrer por entre os prédios de concreto do conhecimento e foge da lógica pragmática e sistêmica das formas de pensar epistemologias dançantes ao abrir caminhos e espaços para criação a partir de si.

Argumenta-se, portanto, a partir das indagações apresentadas neste trabalho, que o intérprete criador em dança é criador e criatura dos seus processos artísticos e estéticos, enfatizando o íntimo processo de singularidade no ato artísticos poéticos em dança, pois tomados de tais potências, torna-se corpo nômade, isto é, máquina de guerra dançante e a partir de um trabalho sensível de tomada de consciência sobre si, cria modos de se perceber-se e de agir diante daquilo que o rodeia. O que me leva a vislumbrar também que, a Coreocartografia familiar pode ser apontada também como uma reflexão consciente sobre os espaços que o artista/bailarino intérprete-criador ocupa socialmente. Tornando-se um procedimento para a estilização da vida e instaurando-se como um plano de agenciamento dos fenômenos entre arte e vida, isto é, um plano de pesquisa em experiência no qual suas diversas manifestações estão tão imbricadas que o fazer e o pensar em dança, que afloram dos encontros dessa coreocartografia se espalham por entre diversos territórios que excedem o fazer dança como um procedimento criativo de ordem pragmática e possibilitam vislumbrar a própria vida como uma obra de arte, isto é, a vida como uma coreografia.

\section{Referências}

DELEUZE, Gilles; GUATTARI, Félix. Mil platôs: capitalismo e esquizofrenia. Rio de Janeiro, 34, 1995.

DELEUZE, Gilles; PARNET, Claire. Diálogos. Trad. Eloisa A. Ribeiro, São Paulo: Escuta, 1998.

FOUCAULT, Michel. História da sexualidade 2: o uso dos prazeres. Trad. Maria Thereza C. Albuquerque. Rio de Janeiro: Edições Graal, 1984.

MORAES, Daniel Silva; JARDIM, Alex Fabiano Correia. O que é uma linha de fuga? considerações a partir do conto "A terceira margem do rio", de Guimarães Rosa. Caderno de estética aplicada, n. 20, Universidade Estadual de Monte Claros (Unimontes), Monte Claros, Brasil, jan./jun. 2017.

NUNES, Kauan Amoras. Trilogia do armário: encenação teatral como prática de liberdade no processo de estilização da vida. Jundiaí [SP]: Paco Editorial, 2019.

OITICICA. Hélio. Esquema geral da nova objetividade. In: OITICICA. Hélio. Aspiro ao grande labirinto. Rio de Janeiro, Rocco, 1986. [originalmente publicado no catálogo da mostra "Nova Objetividade Brasileira". Rio de Janeiro, MAM, 1967].

REIS, Marcelo. Porosidade do corpo na dança do século XXI. In: GOUVEIA, Célia. Dança no século XXI (Org.). 1. ed. Curitiba: Editora Prismas, 2017.

DIAS. Rosa Maria. Arte e vida no pensamento de Nietzsche. Cad. Nietzsche, São Paulo, v. 36 n. 1, p. 227-244, 2015. 
SALLES, Cecilia Almeida. Redes da criação. 2. ed. Vinhedo, SP: Editora Horizonte, 2006.

SALLES, Cecilia Almeida. Gesto inacabado: processo de criação artística. 6. ed. São Paulo: Intermeios, 2013.

SILVA, Eliana Rodrigues. Dança e pós-modernidade. Salvador: EDUFBA, 2005.

SILVA, Juanielson A. Farinha poética: a coreocartografia familiar de um rito artístico. Dissertação de Mestrado. Universidade Federal do pará. Instituto de Ciência das Artes. Programa de pós-graduação em Artes da UFPA: Belém do Pará, 2019.

VIDARTE, Paco. Ética bixa: Proclamação libertária para uma militância LGBTQ. São Paulo, Editora n-1, 2019. 